\title{
A Sociological Study on the Rape, Rapist and the Victim of Rape in Bangladesh
}

\section{Mohammad Alam Chowdhury ${ }^{1}$, Akkas Ahamed ${ }^{2}$ and Md. Sayedur Rahman $^{3}$}

\section{Abstract}

The ratio of rape in Bangladesh has increased dramatically in the recent past. It is happening due to the deterioration in social norms, and other several invisible social reasons. For any society's ethical degradation, there are social, political, economic and cultural reasons. The proportion of rape has not only enhanced in the South Asian countries but also in the developed countries as well. The main objective of this study was to find out the reasons for rape, and to provide with some suggestions for controlling the incidence of rape in Bangladesh. Also, this study has done a historical review on how it can influence society, state, and psycho-physical conditions of the victims. The historical review is very effective in finding out the main causes of rape in any society. Methodologically this is a qualitative research work, based on both primary and secondary sources of data. The article has discussed the nature and inherent causes of the rape which occurred in some South Asian countries with particular emphasis to Bangladesh. Also, the social causes of the increase of rape- incidences in Bangladesh have been discussed and analyzed. The study found that there are a number of examples of rape incidents in Bangladesh. Based on the findings of this study, it is strongly recommended that, the authority should formulate legal framework, proper policies, and should take adequate steps for the proper implementation of the rule and/or law to control rape incidents in the society.

Keywords: Bangladesh, Crime, Law, Mythology, Rape, Rape-victims, Rapists
1,2 Department of Political Science, University of Chittagong, Chittagong, Bangladesh

${ }^{3}$ Department of Political

Science, Faculty of Social

Sciences, Begum Rokeya

University, Rangpur,

Bangladesh

${ }^{3}$ Faculty of World

Economy and International Affairs, National Research University Higher School of Economics, Moscow, Russian Federation

1.malamcu@yahoo.com 2ahamedcu@yahoo.com 3sayedur34@gmail.com 


\section{INTRODUCTION}

There are a lot of sociological reasons behind the rape incidences in Bangladesh. The impacts of these rapes are equally applicable for not only Bangladesh but also for all other countries of the world. The cause of rape is the jeopardy of the society and state, and the distortion in the psychophysical conditions of a man. It does not merely happen based on psychological motives. Physical excitement is the only ingredient and undoubtedly it is a social ailment. Rape is one of the symptoms of many social diseases and these are originated from social disorders. This disease may arise publicly if the ethical and normative values are ruined continuously in the society (Rakha Krishno, 2011). Social norms and values are intermingled inseparably with the human being's mind, soul, and thought. But cultural infertility destroys this bond sharply. As a result, the social harmony continues to be jeopardized. It can never be stopped through the laws in this futile society; because the law works as the external medicine of the skin diseases. Skin disease originates from the contamination of blood in the human anatomy. Thus, this disease can never be eliminated through the treatment of ointments on skins. Likewise, the problem of rape can never be stopped through the killing of some rapists on cross-fires or gun-fires; rather it is important to find out as to where the problem is in the core of the society.
All social diseases originate from social decay. Gradually the disease is growing in the society of Bangladesh. This can be looked at through the lens of social instability. The occurrences of rape are seen in all societies and countries of the world including the developed, developing, and underdeveloped. The cases of rapes are available in the countries of developed political culture as well. Thus, the cultural cause should not be blamed for the incidents of rapes.

The English word 'Rape' came from the Latin word 'rapia' which means seize or, forced snatching. The extreme sexual harassment is called rape. These kinds of incidents are dramatically rising all across the world. In the United States of America, in every six minutes one woman becomes the victim of rape. In the case of India, in every twenty-nine minutes, a woman becomes the victim of rape too. Through these rape incidents, the women are not merely being suppressed and put at risk mentally, but also, they are being isolated from the main stream of the society in terms of politico-economic empowerment (Rakha Krishno, 2011).

\section{SIGNIFICANCE OF THE STUDY}

The main reason for rape is the longlasting ineffective laws of the political system and the observation of rapist in the eye of law insignificantly. Here, some of examples of rape incidents in Bangladesh might be given. For 
example, a boy, Farhad, who was fourteen-year-old, raped a girl in Bangladesh (Rakha Krishno, 2011). Later he stated that, he was stimulated by watching a sex-film at the cost of ten taka at a restaurant the previous night. Then he was mentally so excited. He was trying to find an opportunity where he could meet a girl alone, to rape and test his physical stamina. To have created this kind of environment for Forhad the surrounding circumstances were totally liable. The social and cultural environment through which he went on to build up his mental faculty and mindset was full of numerous mistakes and wrong-doings. So, he became mentally sick at childhood before he turned himself into an adult man. Although he, the rapist Farhad, said that due to pornography he was instigated to the incident of rape the real truth is that Farhad is the byproduct of the decayed society. He is absolutely a solid member and representative of that society. They, Farhad and other rapists, have been created from the social decay of our country. There are many Farhads who are invisible in the society, but are very active in carrying out their misdeeds efficiently. A big number of the people in the society have become the representatives of this ruined and decayed society. Further Obscenity and pornography instigate the spirit of rapist mentality. As a result, at a later time, it helps expedite the mentality into sickness. The case of Farhad is not different from this example. We think that this study is very significant because the incidences of rape are increasing dramatically in Bangladesh. This research has given some policy recommendations to reduce the incidences of rape. The previous researches have focused only on the causes of rape, but had not been able to suggest any policy to address the issue properly.

\section{STUDY OBJECTIVES}

Bangladesh is a developing country of the world with high economic growth. It has much potential in terms of socioeconomic and political development. The country needs to address the issue of rape appropriately for the betterment of the country and for the people. Without solving the problem of rape which is prevalent in the country, development of the country can be stagnant and flawed. Thus, it is very important to carry out research on a social problem like rape, and the causes of rape. The main aim of this research is to provide policy recommendations to curb the spread of the rape incidences across the country.

\section{STUDY METHOD}

Methodologically this is a qualitative study. The authors of this research work have exchanged views with some rapists and rape-victims and have engaged in several focus group discussions to collect reliable data on the issue in the major cities of 
Bangladesh. The purposive sampling method was used to carry out this study because this method is easy to analyze the collected data in a qualitative manner. The researchers of this study are habituated to pursue study in qualitative approach instead of quantitative method. All the primary data have been presented in this research in qualitative method without using any kind of quantitative tools. Also, the researchers have paid visits to Dhaka, Chittagong, Rajshahi, Khulna, Sylhet, Rangpur, Mymensingh, Jessore, Comilla, Bagura, Feni and Cox's Bazar to find out the causes of rapes in Bangladesh. They all have given important inputs to this research work as original contributors. Besides, secondary data have been collected from the relevant journal articles, research monographs, books and newspapers. Thus, this research has intermingled both primary and secondary data in the form of qualitative methods without using any statistical tools.

\section{THE SOCIOLOGICAL DEFINITION OF RAPE}

The culture of rape is being used as a tool of violence against all women all over the world. The simple definition of rape is to involve in sexual intercourse with a woman forcefully without her consent (Ylle and Torres, 2016:2). In general, this torture is being carried on a human being by an inhumane rapist. This kind of culture of rape is absent in the case of beasts.
In the case of Chimpanzees and monkeys that are much known for their naughty activities, we do not see these kinds of inhumane and cruel activities of rape carried out by these beasts. Susan Brown Miller has stated this issue precisely in the first chapter, 'The Mass Psychology of Rape: An Introduction', of her great book "Against Our Will: Men, Women and Rape", "the rapists had to face serious punishments in the ancient Indian and Greek societies for their crimes" (Brown miller, 1975:376). Although in those societies there were many examples of brothels and prostitution; none could have escaped from the crime of rape in those ancient societies.

The criminals, of course, had to face justice and the offenders had been brought under fair trials. In the rules and regulations of Hammurabi, the crime of rape was considered as great offence and thus the capital punishment was ensured for the perpetrators. The great political thinker and an adviser to the then Mourya Empire, Kautillya, also known as Chanakkya and Bishnogupto, inscribed the rules of punishments for the rapists in his world reputed book, 'ArthoShastro'. The definition of rape is done with multiple aspects instead of a single definition. The rape is being considered as an important tool of sexual violence within the ambit of marital agreement. Rape is being occurred in the intimate relationship as well. Diana Russell told in her 
research survey that, the ratio of marital rape is very high in America and it is being occurred regularly which is a serious problem for the American society (Ylle and Torres, 2016:2). Brown miller gave a more acceptable definition of rape. She said, "Rape is a sex crime, an output of a diseased and perverted mind. Rape is a sexual invasion on a body by force, an incursion into the private and personal inner space without her consent. Moreover, rape is an internal assault of the several avenues and several methods of physical and mental tortures. Rape is believed to be a deliberate violation of emotional, physical and rational integrity. And it is a hostile, and a serious act of violence towards humanity and human being" (Brownmiller, 1975:376). On the other hand, Yllo and Torres said, "Rape is a controversial concept. We can define rape simply: forced sexual intercourse without the victim's consent" (Yllo and Torres, 2016:1).

\section{RAPE AND HEROISM IN THE MYTHOLOGY}

The history of rape is very old. The penis of man has not only been used for physical excitement. Sometimes, his heroic stamina, political, social and economic powers have played a special role in showing his superhuman power. Men have only exposed these as symbols of power. There is the heroic verse of rape. Brown miller wrote a chapter on the audacious rapists in her reputed book, "Against Our Wall: Men, Women and Rape" (Brown miller, 1975:376). According to the explanation of Brown miller, the rapists have turned themselves into the iconic power of mythology, politics and society'. Miller has named this chapter, 'The Myth of the Heroic Rapists'. She wrote about the dauntless rapists in that chapter, "People often ask about the classic Greek myths relating to rape. Actually, Greek myths reveal very little about rape. For instance, myths about any given god or goddess are often contradictory. It is too far too easy to retell a Greek myth to fit any interpretation. It does seem evident that on earth and in the sea, the male gods: Zeus, Poseidon, Apollo, Hades and Pan used to rape many women frequently with zest and trickery. Yet on the other hand, the goddesses and mortal women who were victims of these rapes are: Hera, Io, Europa, Cassandra, and Leda. Rarely did they suffer serious consequences beyond getting pregnant and bearing a child, which served to move the story line forward. Hera, Zeus's sister, had a foolproof method of recovery. She would bathe yearly in a river to restore her virginity. Aphrodite was a great champion in seducing many energetic people, according to the Greek Mythology. Philomela was raped by Tereus, King of Thrace who took the precaution of cutting out Philomela's tongue so that she could not tell her story to other people. Philomela cleverly embroidered her woes into a 
piece of needlework that she sent to her sister, Prokne, who happened to be Tereus' wife. In sisterly revenge, Prokne killed Tereus' son. (Latter all of them turned into birds). The young girl, Kainis, who was raped by Poseidon, chose an unusual and highly personal solution to her problems. She asked Poseidon to change her into a man in order to avoid future violations. Kainis, the girl promptly turned herself into Kaineus, the warrior, who worshiped his spear. Zeus's rape of Leda by taking the form of a swan, which resulted in the birth of Helen" (Brownmiller, 1975:283). The statement provided by Miller was from the Greek mythology. There are a huge number of rape histories in the Greek mythology, from which many wars were announced and fought. But these mythologies have no practical evidence. And these mythologies are being applied in the creation of modern knowledge materials.

In the ancient Indian old history, there were many examples of dauntless rapes. Not only were those incidents, many rapists were being worshiped. Thus, till now in many societies the penises are being worshiped. The penis is also a symbol of social dignity and lordship. Therefore, the rape might be the consequence of a social revenge. On grounds of social power and heroism, the wife or daughter of the rival group might be raped. After being held the national elections in Bangladesh, many incidents of this kind occurred. These types of incidents are used in the case of communal riots in India.

An innocent girl has been made victim through mass-rape due to the offence done by her father, mother or brothers in order to preserve the dignity of the particular race. This incident had happened at the Meerwala village of the state of Punjab in Pakistan along the Indian border. Mukhtaran Bibi was raped by a number of people on grounds of racial conflicts and the judgment of the panchayet of a tribal group. Mukhtaran Mai sustained the rape-injuries and had been able to inform the world about the nasty culture and activities of the tribal group in Pakistan. The whole world has become astonished by hearing the news of mass-rape in the name of trials. This incident happened in 2002 (Mai, 2016: 10-11).

The whole event was perpetrated only on grounds of honor and dignity. Mukhtaran was raped inhumanly and ferociously by the tribal group in the name of only preserving the social respect and formality of the tribal group. Mukhtaran could not save herself through the promise in the name Allah and the holy religious book of Al Quran. Based on the event she wrote a book of memoir, titled, 'In the name of honor' where she has stated about the physical and mental tortures which were done to her during the mass-rape. She has written, "In the name of Quran, release me! I scream. In the name of God, let me go!' I pass from one night to another, taken 
from the dark-place to the inside darkhouse, an enclosed place where I can distinguish those four men. There is only a tiny window for the moonlight filtering. There are four walls and a door, protected by an armed silhouette. Escape is impossible from their capture. Prayer is impossible. There are our men: Abdul Khaliq, GulamFarid, Allah Dita, and Mohammad Faiz. I do not know how long that brutal torture lasts. An hour? All night? I, Mukhtaran Bibi, eldest daughter of my father, Gulam Farid Jat, lose all consciousness and talents of myself, but I will never forget the faces of those cruel animals. For them, woman is just an object of possession, honor or retaliation. They are habituated to marry or rape them according to their idea of tribal superiority. They know that a woman humiliated in that way has no other option except suicide. They don't even need to use their weapons and gunfires. Rape kills her. Rape is the ultimate weapon. It disgraces the other clans forever" (Mai 2016: 10-11). The proportion of rape is too high in the African countries. The ratio of being raped is very high in the countries where the issue of ethnic crisis is prevalent. It is well-known to all the incidents of bad examples of rape during the civil wars in Rwanda and Bosnia. This example is similar to the case of racial riots in Gujarat in India, Pakistan, Bangladesh, Myanmar and Nepal, Sri Lanka, Afghanistan and Maldives (Rakha Krishno, 2011).

\section{RAPE AND SOCIAL VALUES}

Social values can be defined as a set of values which are ethically conventional and well acceptable in society. These ideologies are shaped by the changing aspects of the people, organizations in the society, customs, and cultural opinions of the persons in the social order. The rules are mechanisms for persons in society on how to conduct them properly. In the history of the Indian sub-continent, the rape has its own inherent nature. The rape-victim is blamed; and the victim is made criminal for the incident instead of the rapist. The rape-victim family is being harassed socially. The family is being stressed on account of losing personal and social dignity. As a result, the family of the raped viction becomes very serious for hiding the rape-incident instead of demanding justice. In this circumstance, the victim is being raped twice, first by a rapist then by the society where they live permanently. Komala Vasin; an Indian feminist writer and an activist, has told in light of her personal memory, "When I am raped, people say that I have lost my honor". How did I lose my honor? My honor is not in my vagina. It is a patriarchal idea that my rape will define the honor of my community. I would like to tell everyone, why did you place your community's honor in a woman's vagina? We never did that. It is the rapist who loses his honor, we don't. A woman is harassed through the incident of rape in the society. But the rapist moves around on a regular basis. This is something like that, in the body of a 
rapist, the social stigma doesn't touch. The amazing matter is that, the women themselves dishonor the rape-victims. These are the disclosure of the patriarchal mindset. But there are many persons who come ahead to provide helping hands to the rape-victims. That means that the mentality of all men is not the same (Rakha Krishno, 2011).

Rape was a matter of hide once upon a time in the Bangladeshi conservative society. The occurrence of rape was widespread through the breaking down of the wall of conservatism. But, now the incidents of rape are no more an object to be discussed and hide. In every day's daily newspapers, the events of rape are being expressed regularly while taking the issue into serious consideration. This is the nasty face of the nasty society. Rape is being carried out in everywhere, such as village-town, work place, roads, playground, the fields of agriculture, transportations' vehicles, public and private hospitals, clinics, public and private offices, police station, jail, school, college, university and in the houses. There is no time schedule; it happens from morning to noon, afternoon to evening, and night to midnight. "The rape-victims are of different ages: 50, 45, $35,30,25,20,15,10,8,5$, and 3. These victims have come from the different classes and the different professions" (Mohammad, 2012: 187).

\section{THE PATRIARCHY AND RAPE}

Patriarchy is an arrangement of society where the father or oldest man is the head of the whole family and ancestry is figured through the male figure. In Bangladesh a society or community is prepared along male lines. There is a clear link between the patriarchy and rape in Bangladesh. Through the arrangement of patriarchy, the victims are subjugated and ruled; and the perpetrators are given immunity. The Indian feminist writer Komola Vasin has agreed with this notion and she has written, "I know many women who are totally patriarchal in their mindsets. Some of them are totally anti-women; who do nasty things to other women. And I have known many men who have worked for women's rights their whole life. Feminism is not biological: feminism is an ideology (Mohammad, 2012: 187).

The mental stigma after the incident of rape has to be sustained by the rapevictim for the whole life. As a result, normal survival is not possible to her. She has to bear the memory of tortures for her whole life. Her own body becomes unacceptable for herself; and it becomes the source of anguish; because of which she has been fallen sick. In the eve of time, the hatred will be engulfing her centering on her body (Mohammad, 2012: 187). This is called the mental complexity of a woman. Only because of her physical structure, she is made a victim of rape. The physical, mental and social circumstances of the rape-victims are not taken into account while criticizing the issue in people of the society. In the Bangladesh's society, a rape-victim 


\section{Original Article}

is victimized several times by the different ways including harsh criticism. It continues for the whole life. For instance, firstly, she is raped in front of a rapist; secondly, at the time of medical test in front of the doctors and health workers; thirdly, at the time of witnessing and hearing at the court in front of large crowd; and fourthly, she will be being raped throughout her life through social criticism. It seems that, in Bangladesh the rapist is not the real culprit; rather the rape-victim is being taken into account as the real perpetrator. Not merely in Bangladesh, this is applicable to all the countries of the world.

Most of the people of Bangladesh are habituated to collect at least fivecharacter certificates in their hands (Rakha Krishno, 2011). Hitherto, the cause of bad character is ignorance. The literate persons who have obtained institutional certificates for subsistence, are also involved in rape crimes. The tarnished rape case in Bangladesh is about a female student of Vikarunnesa Noon School and College, who was raped by her teacher, Parimol Joydhar. Then from the priest to labor none is excluded from the incident of rape. There are different kinds of people who have lost the capacity of sexual intercourse, but have not lost their desire to be involved in rape. They point out to women's movements, make-up and dress-up as the potential causes of rape incidents in South Asian countries. But, if this is true, the priests of church cannot control their sexual desire having been dressed with so many clothes. The offence is not related with wearing so many in dresses; rather it remains in the mindsets of people. The instigation of rape is being encouraged through the psychological motives. Only the physical organs of the anatomy are covered through wearing clothes, not perverted desire of the sexual torture or rape (Rakha Krishno, 2011).

Bangladesh is gradually becoming a safe zone for the rapists. There is a relationship between patriarchy and rape incidences in Bangladesh. Also, a huge number of young people are involved in rape. Lack of the proper implementation of the rule of law, and the culture of impunity in the legal process are the root causes of rape in the country. Political leaders with huge money and bureaucratic powers are given priority in the due process of law (Rakha Krishno, 2011).

The familiar faces are being involved in the rape cases unveiling their mask. The perpetrators are involved in raping old woman and baby; and a mad of the street too not safe from those criminals. The perverted face of the society has started to come to light through these notorious incidents. These offenders are well known to all the members of the society. But none is taking them into the consideration of criminals in the society. 
They are coming out of the jail on bail on account of their political affiliation. If these criminals are not prevented from the wrongdoings through social resistance, the whole social system will be jeopardized. Increasingly the penisoriented cowards are becoming dangerous in society instead of the horn-oriented animals. There are many causes regarding the increase of the incidents of rape. For instance: lack of exemplary punishments to the rapists, procrastination in the process of legal proceedings, political patronization to the rapists by the different political parties and leaders, and in some cases the rapists are economically solvent through which they can easily influence others involved in the legal matters. Many women are being raped by not only the relatives, but also by some familiar people. Many of the rape-victims do not unveil the incidents of rape on account of public-shame. If the cultures of the lack of trials are pervasive in a society for long time, in that case, the notorious example of the incidence of rape is usual to happen (Rakha Krishno, 2011).

The incidence of rape is pre-planned, and it is not the exposure of unaware mind (Azad 1992:247). "Rape is a widespread task in Bangladesh, which might not be compared to any other countries of the world. In Bangladesh, the rape is carried out individually, and is gang-raped; and when the rape incidence is over, she is killed brutally. Here, the daughter is raped by her father, daughter-in-law is raped by her father-in-law; and boyfriend rapes his girlfriend. Bureaucratic officer rapes his female clerk; house tutor rapes his female student. Imam (religious teacher in Islam) rapes his female student, who comes in the Madrasah for studying the holy Quran. Sister -in -law is raped by her brother -in -law. And the father-in-law rapes his daughter in law. A huge number of unrelated rapes are occurring across the country (Azad 1992:247).

Political culture of rape creates a deadly environment in the society. Particularly in the developing countries, this propensity is increasing. The tendency has turned into a dangerous one in the Indian subcontinent. Many baba (so called religious father in Indian religious culture), have been continuing the rape activities in the Indian society through claiming themselves as religious masters (Azad, 1992:247). Examples of this kind are also remaining in both Bangladesh and Pakistan. Many criminals of this kind have been taken to the police custody to be brought to justice in India. Among these baba, (fathers): Swami Nityananda, AshraramBapu, Narayan Sai, SatiyaSai Baba, KripaluMaharaj, Rajonish, Isadhohori Baba Bemanada, Guru Gurmeet Ram Rohim Sing, MoharishiMoheshYugi, Swami Rabi Shanker are mentionable (Banu, 2019). Rape is very common matter in the India society. The largest state in India in terms of rape is: Madhya Pradesh. 
Then the Judpur of Rajasthan and Delhi is ranked second and third, respectively in terms of rape incidences in India (Azad, 1992:247).

The social trial (Salish) of rape is being conducted in Bangladesh, where two types of decisions are being taken. First, it is the compensation as the punishment of rape and second it is the proposal of marriage with the rapist. In real sense, the punishment for the crime of rape should not be solved with marriage or financial compensation. Consequently, there is displeasure among the family members and the rape-victim; they remain silent on account of social dignity and security. Moreover, the incidence is solved by convincing the law enforcing agency through bribery. Therefore, the number of rape cases is higher in villages compared to the cities. But on account of the procrastination of the trials, they keep silent and do not feel encouraged to take shelter of law. The incidences of rape in the city area easily come to newspapers and different media, through which it is being widespread throughout the country. But now the incidence is being taken into account as a normal event. The rape-victim and her family are reluctant to go to the court on account of legal injustice and suppression.

In various disciplines of social sciences and medical sciences, the causes of rape have been examined. In general, the ratio of the incidences of rape is high in those countries where the proportion of political and social instability is higher; because in these countries, the role of law is weak through which the culprits can get a chance to commit various crimes including rape. And the offenders also can get an opportunity to get rid of allegations due to their political affiliations to some political parties or close engagement with local and national level party leaders. These kinds of examples are innumerable in the cases of the most South Asian countries. In addition to this, where there is a crisis of ethnic conflicts, rape is more likely to be committed by the majority group of race or by the armed forces, which is directly backed by the ruling government. Not only had that, in some cases, the law enforcing agencies of the state spontaneously involved in rape crimes. In this case, the rapists are not held responsible for the crime; and they are not brought to justice. Where the protector is the consumer, there is no possibility of upholding the free and fair justice; and here law has nothing to do.

As shown in the Bengali cinemas that, there are pre-planned rape, forceful rape, rape on account of political reason, and rape in the hands of miscreants. Viewers would like to clap loudly when they watch a girl being raped by a villain in the cinema. Director of cinema is committed to entertain the viewers through the scene of rape, but he does not know that he is doing a mistake through which the new generation of the 
nation is being interested in rape, and because of which the mind and attitude of viewers are being perverted to the desire of rape. Their mindsets are abnormal for a long time. For a perverted mind, it is quite impossible to think positively and honestly (Rakha Krishno, 2011). This is how cultural destitution attacks on the core of society. In a nutshell, it can be said that the cultural movements play an important role against the incidence of rape in the society. In this regard, the cultural organization should play a pivotal role. Cultural ruin too instigates the occurrence of rape. Cultural functions are required in a society to make proper space for the adolescents so that they can enjoy properly. The certified literate persons are involved in planned rape; and the uneducated and illiterate people are involved in unplanned rape. Sometimes, they involve themselves with the incidence of rape to show heroism to their friends. Cultural awareness teaches that, being involved in rape is not an act of bravery rather it is the violent exposure of the abnormal attitudes. It is not pleasure, rather it is an act of serious offence. The so-called sex stimulating literary publications should be stopped to prevent the rate of rape. From the various corners, the social movements should be organized to prevent crimes.

Rape is the name of perverted stage of our society in the context of current history. To undermine the dignity of women in the society, the men exercise the culture of rape. It is an old social crime. The crime of rape is occurred on account of wars, social conflicts, racial competition, religious rivalry and mental sickness. It is well-known to all that the women are captured and raped when the winners have been able to defeat the opposite party in battle grounds. Due to the mental shock over female lover's fraud a man becomes aggressive towards rape. In this case, the man hates the entire female society. Rasu Khan, a serial killer of Faridganj sub district of Faridpur district, is a rapist of this kind. He is a penalized defendant for many killings. All the women who were raped by Rasu Khan were killed. According to his statement, he raped eleven women and all of whom were killed by him at the same time. He had a plan to rape and to kill one-hundred women. He used to pass his time at Mazar (Shrine of Islamic Sufi) Rasu Khan is totally different in killing the rape-victims. He used to kill the victims through sinking the head into the water. These are his stupidity and extreme mental illness, nothing else. Other killers do the same thing differently. For instance: they throw acid at rape-victims. Some of the rapists kill the victims through sharp weapons, and by shooting. Thus, in the context of rise of proportion of rape in the society, mental diseases are reasonably responsible.

There were many examples of rules to ensure penalty to the rape-offenders in the different times of history. In the 
reign of Hammurabi (1810-1750 B.C), there were the following penal-codes for the crime of rape: "Rape of virgin, then, became a crime that damaged the property of her father-devaluing the price he could achieve for her as a bride. This view can be seen in the Babylonian Code of Hammurabi, which dates from about 1780 B.C. According to Hammurabi's code, virgins were considered innocent if raped, but their attackers were executed. However, a married woman who was raped was considered to be guilty of adultery. Both she and her rapist were executed by being thrown in the river, although her husband had the right to save her, if she wished to do so" (Smith 2004: 14-15). Yet, through this process the criminal could be identified properly. Special attention had to be drawn so that any innocent people could not be convicted. But in the case of Bangladesh, the innocent people are convicted through the transaction of bribe. Also here, the innocent people are being compelled to do crime through political patronization and political criminalization. In the ancient India, the penis would have been beaten with a weapon for the crime of rape, or the penis would have been broken down with a small weapon.

\section{PHYSICAL AND MENTAL CONDITION OF VICTIM AFTER BEING RAPED}

After being raped, a woman becomes mentally and physically upset. The entire society of women is involved in struggles. The women are to sustain with many fears at homes, at work places, and at prayer places. Everywhere they are obliged to survive dangerous situations. The source of this fear is multifaceted. The fear does not come from the fourlegged animals. Rather it comes from the so-called well-dressed and dual standard men. According to a proverb in Indian old history, the deer-like body of a woman has turned her into the prey of a heinous man. The main cause of this offence is related to the bad character of male society. There are always wars declared against the women in society in our social systems. Where the women's bodies are condemned for being the victims of rape, the men are not blamed at all for their crimes. The social perceptions towards women are explicitly negative. And the tendency of rapecrime is gradually increasing in the society. The wars which were carried out from the ancient time to the present, the women's bodies have been blooded. In the battle grounds, rape has been used as a cold warweapon (Hirschauer, 2014:76). Rape makes a woman frustrated physically and psychologically. Socially they are being turned into the object of dishonor and hatred. They are also being financially spoiled. These are happening on account of social dogmatism and superstition; because in patriarchal society, it is perceived that the incidences of rapes usually occur due to their unruly movements 
through which their virginity is put at risk. Although the virginity of a woman is hampered on rape, the humanity of a man is not jeopardized or destroyed. In this way, the culture of injustice is spread up not only in the societies of South Asia, but also in the whole world.

From many aspects, it is observed that, many incidences of rapes have to be hidden due to the involvements of very intimate persons, or due to the involvements of close relatives. Though the rapist is roaming around after perpetrating rape, there is none to stand up against him, or there is none to take actions against the rapist. In that case, the victim has to sustain with many agonies. "When they talk about sexual abuse, rape and incest, actions and others do not always use terms precisely". "Molestation", "sexual assault" and "outraging the modesty" are the additional terms that are sometimes used without definition (Hayward, 2000:83).

None of the biological species is to face such painful circumstances like women in the society. Here the religions are also against women. The culture of hating rape-victims has been originated from the religiosity since the religions claim early marriage with virginity from a woman. On the other hand, the question of the fairness of virginity has remained evaded for the men. This is how men are encouraged to be involved in the crime of rapes. Despite this, the mark of evil-luck of rape is being inscribed on the body of a victim. To the eyes of relatives, sons, daughters and husband, she remains a culprit. At this point, clever men always glare at the victim to invade her again, if any chance comes to him. This can be said as a life-long penalty for a victim. Besides, a rapist has to confront a mild punishment. It has been observed in the trial of rape that the victim's pains have been exacerbated multiple times through her statement in front of the public (Hoque 1996:133).

If any declaration comes from the men's society that they are not perfect; there will be no harm to women in the society or to any woman. Women will not have to say as the feminist writer Margaret Lucas has stated "the men are extremely injudicious towards us and carry out inhumane activities against us. They enjoy all kinds of freedom; but we are not allowed to enjoy our freedom at all. Even they do not permit us to exchange views with our friends, the women. We live in a society like monkeys or other animals. We are like animals that bear many burdens on their necks. We will die like other beasts." (Okaly and Mitchell, 1976: 389).

\section{POLICY RECOMMENDATIONS}

There must be a particular punishment for the offence of rape. If the culprits are taken into fair justice, then the proportion of rape will be reduced in the South Asian countries including Bangladesh. Otherwise, the tendency 
of criminality will continue to rise. In Bangladesh, usually the local elites are actively involved in conducting this kind of trial; and they solve the issue within a night through sitting on the premise of a house. Thus, the punishment for a tarnished crime is just a minor reimbursement. All members of the civil society should come forward to inspire social movements against rapes. The concept of virginity is patriarchal. Apart from these, the government institutions, political parties, civil society members, academicians, NGOs, UN and other local and international organization should come forward to tackle the issue of rape with utmost sincerity.

\section{CONCLUSION}

Rape has been prevailing as a notorious crime since the very beginning of the human civilization. Its nature is different only from cultural differences around the world. The seed of rape is sown in the political, economic, social religious and cultural issues. Rape is not an uncontainable social crime. Formulation of legal frame works is important with proper implementation of law to curb the rate of rape incidences. Moreover, families of victims should not be hated, and rather should be taken into special care. Besides, social movements against rapes are highly important to root out the culture of rapes. New policies and laws are extremely important to prevent the crime of rape. The proper implementation of the role of law is very substantial in curbing the incidences of rape. Good governance and neutral attitudes of the law enforcing agencies are also pivotal to combat the culture of rape. Political affiliations of the criminals should be stopped. And the offenders must not be given political shelter by the ruling government. In a nutshell, the independence of the judiciary is so significant to prevent the incidences of rapes through which the fair trial can be ensured for the rapist. And the victims should be given due rights and privileges in the judicial process as well.

\section{References}

Azad, H. (1992). Women, Agami Publication, Dhaka.

Brownmiller, S. (1975). Against our will: Men, women, and rape. Ballantine Books.

Banu, S. (31 July 2019). 10 Curious Scandals of Indian Swamis, (Accessed, http://www.wonderslist.com/10curious-scandals-of-indian-swamis/

Haque, M. S. (1996). Dictionary of Women, Tarafdar Publication, Dhaka.

Heyward, R. F. (2000). Breaking the Earthenware Jar: Lessons from South Asia to End Violence against Women and Girls, UNICEF Regional Office for the South Asia, Kathmandu, Nepal.

Hirschauer, S. (2014). The securitization of rape: Women, war and sexual violence. Springer.

Mai, M., \& Cuny, M. T. (2006). In the name of honor: A memoir. Simon and Schuster.

Mohammad, A. (2012). Women, Men and Society, Sanghati Publication, Dhaka.

Okaly, A. and Mtchell (1976). The Rights and Wrongs of Women, Penguin Books Ltds, England.

Rakha krishno, D. (2011). Women Torturing and Teasing, cited in the 'Women World: Compilled by Bohuswar, edited by Bashovi Chakraborty, Urboshi Publication, Kolkata. 
Smith, M. D. (ed.), (2004). Encyclopaedia of Rape, Greenwood Press, London.

Yllo, K., \& Torres, M. G. (Eds.). (2016). Marital rape: Consent, marriage, and social change in global context. Oxford University Press. 